В.А. Иноземцев, И.А. Нельга, И.В. Медвецкий, С.А. Комиссаренко, А.В. Злобин, С.В. Третьяков, А.В. Шерстюк.
Федеральное государственное бюджетное учреждение
«33 Центральный научно-исследовательский испытательный институт»
Министерства обороны Российской Федерации, 412918,
Российская Федерация, г. Вольск-18, Краснознаменная, д. 1

Поступила 26.05.2020 г. Принята к публикации 06.06.2020 г.

Отдельные фосфорорганические соединения обладают высокой токсичностью и могут быть использованы в качестве боевых отравляющих веществ (ОВ). Однако некоторые классы органических соединений фосфора могут вызывать так называемую отсроченную нейротоксичность. С момента открытия в 1899 г. и до настоящего времени проводятся обширные исследования отсроченной нейротоксичности, вызванной фосфорорганическими соединениями. Массовые отравления жителей США и Марокко в прошлом веке продемонстрировали высокую опасность веществ, вызывающих нейротоксичность, и дали мощнейший толчок исследованиям этого явления. Кроме отсроченных эффектов, некоторые соединения фосфора усиливают действие уже известных боевых ОВ, повышая их токсичность более чем в 10 раз. Исследования в этом направлении ведутся под эгидой оборонных ведомств США, Канады и Нидерландов. Широкое распространение соединений фосфора в различных отраслях промышленности и сельского хозяйства, длительный скрытый период и необратимость поражений, вызываемых нейротоксичными ФОС, обуславливают их потенциальную угрозу для безопасности Российской Федерации.

Ключевые слова: нейропатическая эстераза; органические соединения фосфора; отсроченная нейротоксичность; синергизм; триортокрезилфосфат.

Библиографическое описание: Иноземцев В.А., Нельга И.А., Медвецкий И.В., Комиссаренко С.А., Злобин А.В., Третьяков С.В., Шерстюк А.В. История зарубежных исследований отсроченной нейротоксичности, вызванной фосфорорганическими соединениями // Вестник войск РХБ защциты. 2020. T. 4. № 2. C. 177-188. https://doi.org/10.35825/2587-57282020-4-2-177-188

Ранее нами были рассмотрены основные вехи зарубежных исследований фосфорорганических отравляющих веществ (ОВ), использовавшихся в качестве ключевых компонентов химического оружия [1]. Однако некоторые классы органических соединений фосфора могут вызывать так называемую отсроченную нейротоксичность ${ }^{1}$. С момента открытия и до настоящего времени токсикологами проводятся обширные исследования этого явления.
Цель работы - ретроспективный анализ зарубежных исследований отсроченной нейротоксичности, вызванной фосфорорганическими соединениями ${ }^{2}$.

Открытие и начало исследований отсроченной нейротоксичности.

Первые задокументированные случаи возникновения отсроченной нейротоксичности, вызванной фосфорорганическими соединениями (ОНТФОС), относятся к 1899 г., когда

\footnotetext{
1 Нейротоксичность - способность химических веществ, действуя на организм, вызывать нарушение структуры и/или функций нервной системы.

2 В англоязычной научной литературе наиболее часто употребляется аббревиатура OPIDN - Organophosphate Induced Delayed Neuropathy.
} 


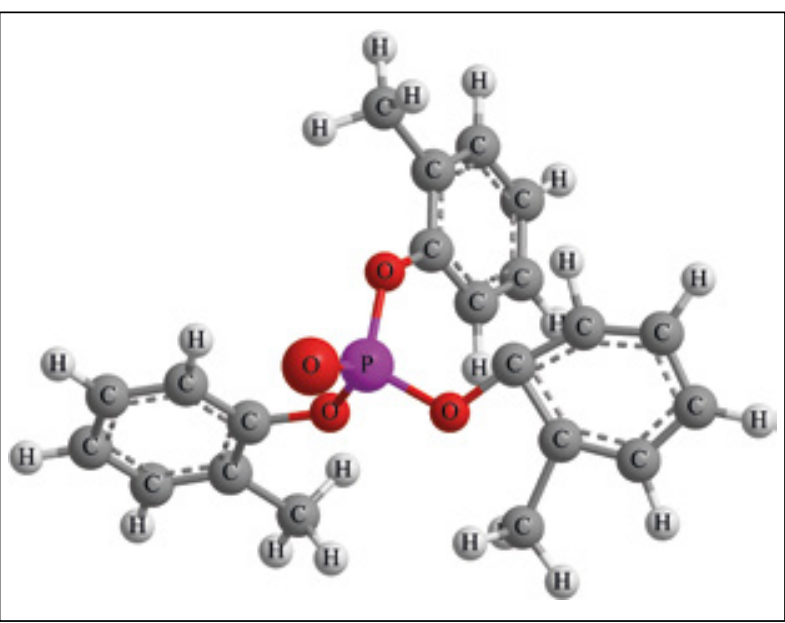

Рисунок 1 - Модель молекулы триортокрезилфосфата (URL: https://en.wikipedia.org/wiki/ Tricresyl_phosphate; дата обращения: 15.05.2020 г.)

французский исследователь С. Lorot в своем докладе [2] описал нейропатию, поражавшую больных туберкулезом, которые принимали в качестве лекарства смесь эфиров фосфорной кислоты, полученных фосфорилированием каменноугольной смолы. В общем случае заболевание проявлялось в развитии атаксии, парезов, восходящего паралича, в тяжелой форме приводивших к смерти. Наибольшее количество пострадавших - более 50 тыс. человек было зафиксировано в США в тридцатых годах прошлого века [3].

Первые случаи неизвестной болезни были описаны врачом Центрального госпиталя г. Цинциннати (шт. Огайо) доктором T.J. LeBlanc. Всего им было описано более 200 случаев, причем первый заболевший поступил во второй половине февраля, пик заболеваемости пришелся на март, а к апрелю «эпидемия» пошла на спад. В это же время Департаментом здравоохранения штата Теннесси (г. Нэшвил) зарегистрировано 119 схожих случаев. Большую часть пациентов составляли мужчины в возрасте от 20 до 80 лет [4].

Изначально врачи придерживались инфекционной теории возникновения болезни, однако скоро «виновный» был обнаружен - им оказался триортокрезилфосфат (ТОКФ), содержавшийся в партии имбирного экстракта «Ginger Jake» (рисунки 1 и 2).

Он приобрел популярность в годы Сухого закона ${ }^{3}$ в США в качестве вкусовой и ароматизирующей добавки к кустарно производимому алкоголю.

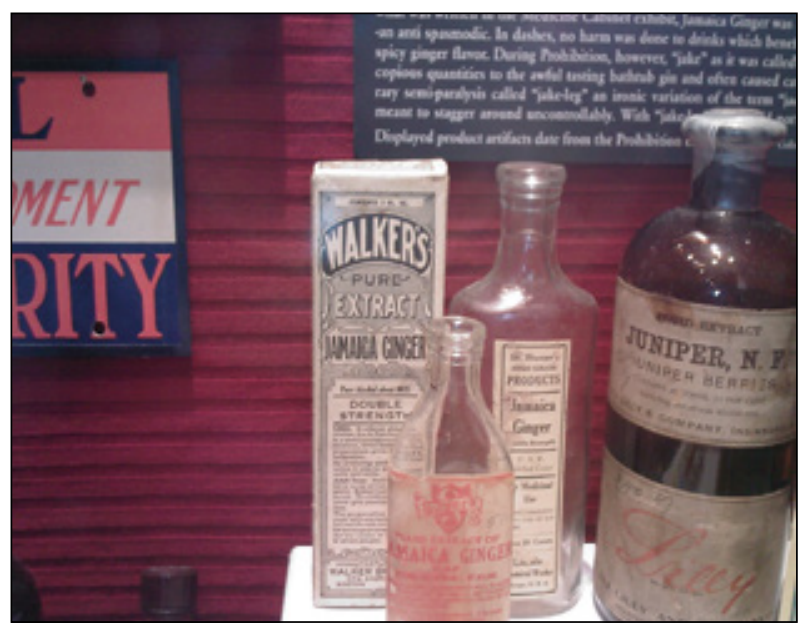

Рисунок 2 - Образцы упаковок спиртовых экстрактов имбиря

(URL: https://upload.wikimedia.org/wikipedia/en/ thumb/c/c8Jamaican_ginger.jpg/1024px-Jamaican_ ginger.jpg; дата обращения: 15.05.2020 г.)

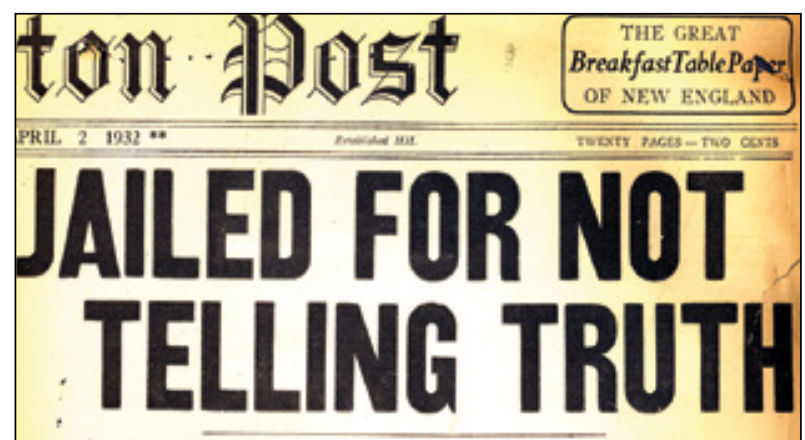

Shipper of Poison Jamaica Ginger Given Probation Year Ago on Promise to Help Government Locate Producer--.-8fficials Find He Lied--.-Was Himself the Manufacturer

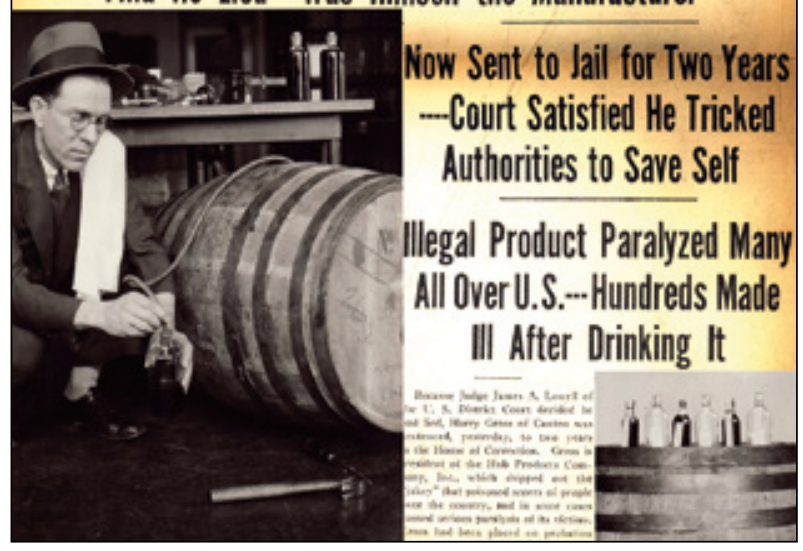

Рисунок 3 - Образцы упаковок спиртовых экстрактов имбиря

(URL: https://upload.wikimedia.org/wikipedia/en/ thumb/c/c8Jamaican_ginger.jpg/1024px-Jamaican_ ginger.jpg; дата обращения: 15.05.2020 г.)

\footnotetext{
Сухой закон - общенациональный запрет на продажу, производство и транспортировку алкоголя, который действовал в США с 1920 по 1933 г.
} 

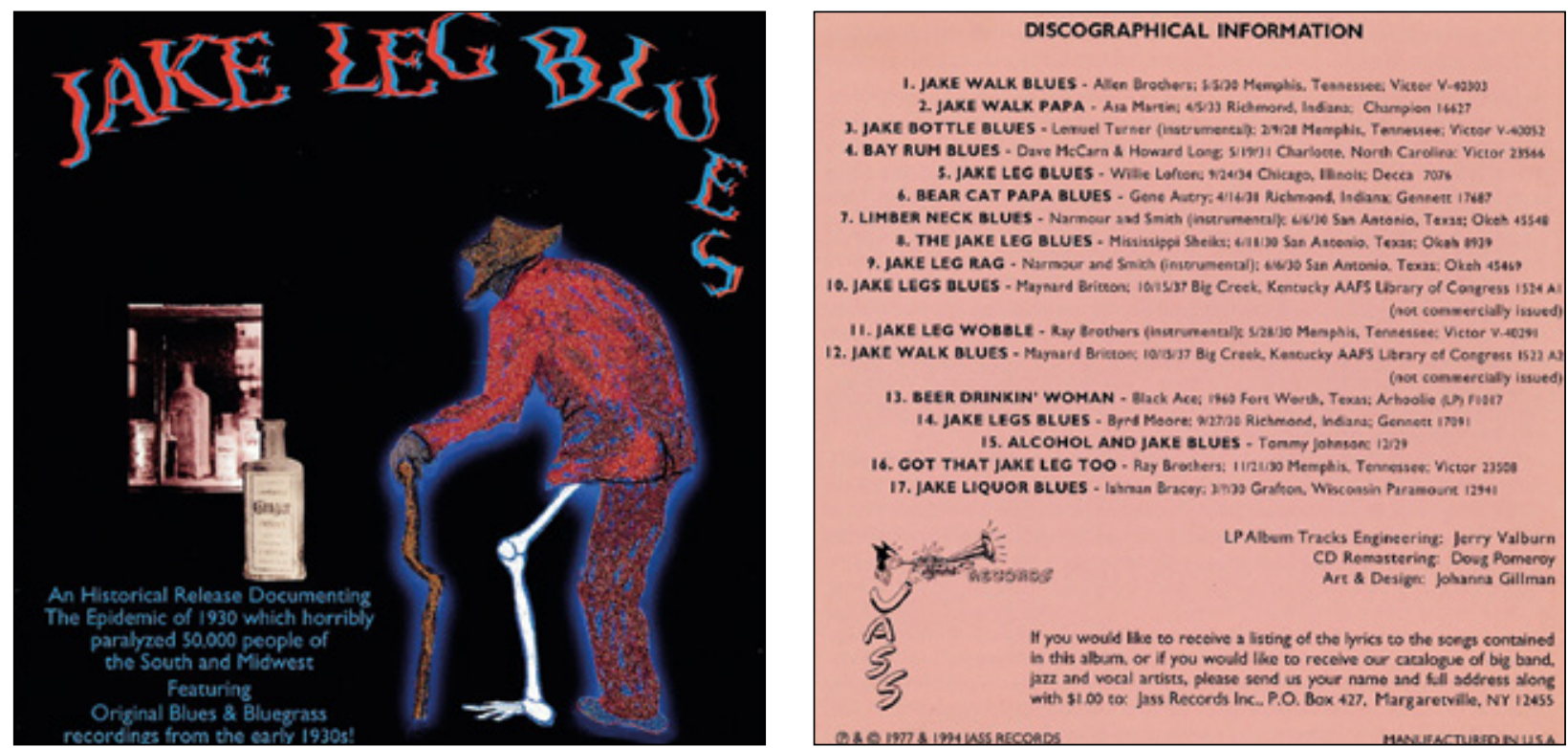

Рисунок 4 - Обложка сборника джазовых композиций, популярных в 30-е годы прошлого века (URL: https://www.discogs.com/ru/release/5374288-Jake-Leg-Blues/images; dama обращения: 15.05.2020 г.) дата обращения: 15.05.2020 г.)

С легкой руки журналистов, достаточно активно освещавших эти трагические события, совокупность симптомов получила наименования «имбирный паралич», «походка Джека» («Jake Walk»), «нога Джека» («Jake Leg») (рисунок 3).

Интересно отметить, что эти события нашли широкое отражение в американской массовой культуре. На рисунке 4 представлена обложка музыкального сборника джазовых композиций, популярных в 30-е годы прошлого века. Названия отдельных композиций и сборника в целом включают словосочетание «Jake Leg».

Не только жители США становились жертвами отравления триортокрезилфосфатом. В 1959 г. аналогичная трагедия произошла в Марокко. Первые случаи были зафиксированы в период с 31 августа по 2 сентября 1959 г., затем, в период с 18 по 24 сентября того же года, ежедневно поступали от 200 до 300 пострадавших. К 2 октября число жертв составляло уже более 2 тыс. человек. К 18 ноября число жертв превышало уже 10 тыс. человек [5]. Как и в предыдущем случае, мнения врачей относительно источника заболевания разделились - главенствующей была инфекционная, возможно, вирусная теория. Также рассматривалась теория, связанная с массовым отравлением, нашедшая вскоре подтверждение - источником болезни явилось «оливковое» масло, щедро (более 70 \%!) разбавленное недобросовестным поставщиком синтетическими техническими маслами, содержавшими ТОКФ.

Всего же в период с 1899 по 1988 г. описано не менее 18 случаев массового отравления данным соединением [6]. Сводные данные по количеству пострадавших представлены в таблице 1.

Основной причиной отравлений являлось употребление пищи или алкоголя, контаминированных ТОКФ [6]. Триортокрезилфосфат обладает низкой острой токсичностью (средняя смертельная доза при пероральном введении белым крысам составляет 1160 мг/кг) и является далеко не единственным фосфорорганическим соединением, вызывающим ОНТФОС. Естественно, столь масштабное явление не осталось без внимания исследователей - с конца 1960-х гг. началось активное изучение причин и механизмов возникновения ОНТФОС.

Причины возникновения и механизмы формирования отсроченной нейротоксичности. Накопленный к 70-м гг. прошлого века опыт исследований соединений, вызывающих ОНТФОС, показывал, что при их воздействии, особенно при длительном контакте, наблюдаются расстройства функции периферической нервной системы, выражающиеся в невритах, парезах, атаксии и параличах конечностей. Ocновные патологические проявления ОНТФОС выражаются в двусторонней симметричной дегенерации сенсорных и моторных аксонов в дистальных областях периферических нервов и путей спинного мозга. Аксоны, имеющие наибольшую длину и диаметр, поражаются в первую очередь. Наиболее заметные поражения локализуются в дорсальных пучках шейного отдела спинного мозга, особенно в fasciculus gracilis. Помимо описанных выше симптомов, наблюдаются специфические сенсорные нарушения - потеря распознавания положения 
V.A. Inozemtsev, I.A. Nelga, I.V. Medvetsky, S.A. Komissarenko et al.

Таблица 1 - Сводные данные по массовым отравлениям ТОКФ [6]

\begin{tabular}{|c|c|c|}
\hline Год & $\begin{array}{c}\text { Страна } \\
\text { (страны, регион) }\end{array}$ & Число жертв \\
\hline 1899 & Франция & 59 \\
\hline с 1925 по 1934 & Франция, Германия, Швейцария & от 200 до 500 \\
\hline с 1930 по 1931 & США & более 50000 \\
\hline 1937 & Южная Африка & 600 \\
\hline 1940 & Швейцария & 80 \\
\hline 1942 & Великобритания & 3 \\
\hline с 1943 по 1947 & Германия & от 10 до 20 \\
\hline 1945 & Великобритания & 17 \\
\hline 1947 & Швейцария & 73 \\
\hline 1952 & Швейцария & 80 \\
\hline 1955 & Южная Африка & 11 \\
\hline 1955 & Марокко & 10000 \\
\hline 1960 & Индия & 58 \\
\hline 1966 & Румыния & 12 \\
\hline 1967 & Фиджи & 56 \\
\hline 1973 & Марокко & 40 \\
\hline с 1977 по 1988 & Шри-Ланка & 23 \\
\hline 1988 & Индия & 2 \\
\hline
\end{tabular}

конечностей в пространстве и потеря чувствительности к вибрации [7].

Первоначально, основываясь на симптоматике и наблюдаемой при вскрытии патологической картине отравления, эти явления связывали с демиелинизацией аксонов ${ }^{4}$ и перерождением нервных клеток. Вся группа соединений в профессиональной литературе того времени относилась к демиелинизирующим веществам [8]. Уже позднее было установлено, что первоначально поражается именно аксон, а демиелинизация является следствием. Протекающий процесс можно описать как «химическое рассечение» аксона с последующей валлеровой дегенерацией ${ }^{5}$ [7].

Однако, несмотря на обилие клинических случаев, причины развития столь специфических симптомов долгое время были неизвестны. Прорыв в исследованиях произошел в 1969 г., когда доктор Мартин Кейт Джонсон (рисунок 5) опубликовал несколько работ [911], посвященных исследованию необратимого фосфорилирования специфического белка, названного им «нейротоксической эстеразой» (neurotoxic esterase - NTE) ${ }^{6}$.

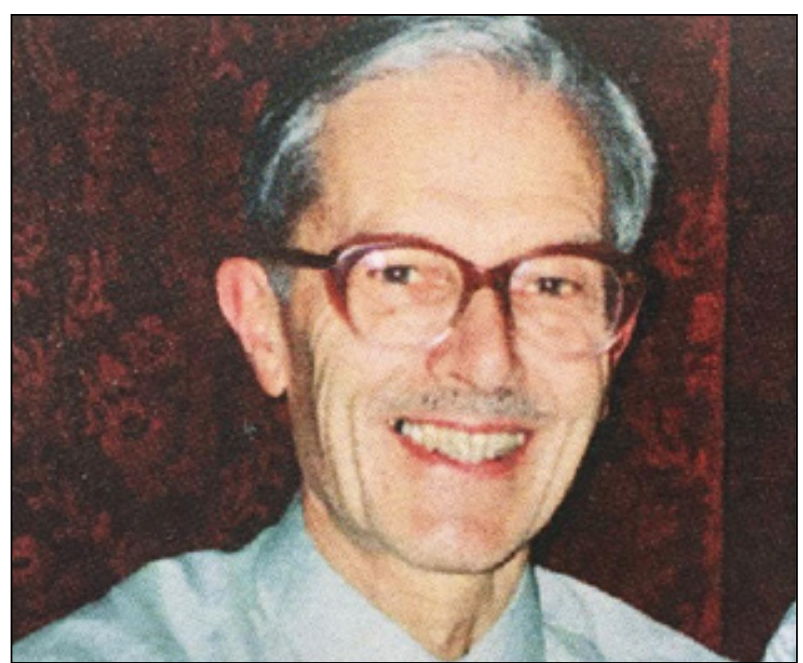

Рисунок 5 - Мартин Кейт Джонсон (Martin Keith Johnson, 1930-2018). Один из первых ученых, занявшийся фундаментальным исследованием явления ОНТФОС. Долгое время являлся сотрудником Отдела токсикологии Британского медицинского исследовательского совета (URL: https:// www.thebts.org/news/obituary-for-\%EF\%BB\%BFdrmartin-johnson; дата обращения: 15.05.2020 г.)

\footnotetext{
4 Аксон - длинный цилиндрический отросток нервной клетки, по которому нервные импульсы идут от тела клетки (сомы) к иннервируемым органам и другим нервным клеткам.

5 Валлерова дегенерация - описанный в 1850 г. нейрофизиологом Августом Валлером (Augustus Volney Waller; 1816-1870) процесс специфического разрушения участка аксона, отделенного от основной части нейрона.

6 Позднее, когда был установлен точный механизм развития поражения, научное сообщество отказалось от этого не вполне удачного термина, однако английская аббревиатура прочно вошла в обиход и для преодоления разночтений была введена ее новая расшифровка: NTE - neuropathy target esterase (нейропатическая эстераза).
} 
В одной из первых работ доктор М.К. Джонсон описал открытие макромолекулярного сайта в тканях мозга кур, специфически связывающего меченные молекулы диизопропилфторфосфата, и сделал предположение о его возможной природе [10]. Впоследствии теория белкового строения нашла экспериментальное подтверждение [11]. Сейчас известно, что NTE представляет собой мембраносвязанную фенилвалериатгидролазу, состоящую из двух субъединиц с молекулярной массой 155 и 119 кДа [12]. Ее необратимое ингибирование запускает каскад процессов, приводящих к гибели аксона, демиелинизации и развитию необратимых последствий для организма. Более подробно современные представления о строении NTE и ее биологической функции приведены в статье [13].

В последующем М.К. Джонсон и возглавляемая им научная группа обследовали более 220 соединений, предположительно, вызывающих ОНТФОС [14]. В качестве модельного объекта для исследований были выбраны взрослые куры, как наиболее чувствительные к нейротоксическому воздействию ФОС животные. Кроме кур, только у кошек и у людей развитие патологического процесса происходит после однократного воздействия нейротоксиканта. В качестве основного критерия развития ОНТФОС было выбрано появление атаксии после однократного введения вещества. В результате исследований было установлено, что тяжелые последствия для организма вызывает только воздействие веществ, необратимо ингибирующих NTE на $75 \%$ и более.

Исследователями были выявлены классы химических соединений, способных вызывать отсроченную нейротоксичность. Например, необратимо ингибируют NTE соединения, относящиеся к классам фосфонатов, фосфатов и амидофосфатов. Фосфинаты, сульфонаты и карбаматы, напротив, являются обратимыми ингибиторами и могут оказывать защитное действие на организм. Еще одним необходимым условием является наличие в структуре соединения заместителей с высокой гидрофобностью. Тионфосфаты обладают меньшей активностью in vivo и не ингибируют НТЭ in vitro. Полученные экспериментальные данные позволили существенно интенсифицировать систематическое изучение ОНТФОС. Помимо М.К. Джонсона, существенный вклад в исследование отсроченной нейротоксичности внесли Морифуса Это (Morifusa Jeto), Джон Е. Касида (Dzhon E. Kasida), Мохамед Абу-Дония (Mohamed AbuDonija) и многие другие.
Прикладные исследования отсроченной нейротоксичности - от пестицидов к оружию. Современное состояние. Расширение исследований различных аспектов отсроченной нейротоксичности позволило выявить, что некоторые коммерческие фосфорорганические инсектицидные препараты, несмотря на относительно низкую острую токсичность для теплокровных, также способны вызывать ОНТФОС. Этому способствовали как направленные исследования, так и анализ случаев массового заболевания среди персонала химических производств, специализирующихся на выпуске пестицидов [8], а также анализ случайных или преднамеренных отравлений указанными препаратами. Например, изображенный на рисунке 6 препарат ЭПН (международное торговое название - EPN-300) при средней смертельной токсодозе от 50 до 100 мг/кг (мыши, перорально) [15] при том же пути поступления вызывает эффекты отсроченной нейротоксичности в дозе 20 мг/кг [16]. Другой пестицид - лептофос (международное торговое название - Phosvel) при средней смертельной токсодозе 71 мг/кг (мыши, перорально) обладает отсроченной нейротоксичностью в дозе 30 мг/кг [16].

Некоторые представители пестицидов, обладающих отсроченной нейротоксичностью, представлены на рисунке 6.

По результатам проведенных исследований фосфорорганические пестициды, вызывающие ОНТФОС, были запрещены к использованию, а их производство прекращено.

Также в ходе проведения исследований был установлен интереснейший факт - ТОКФ, вызывающий клинические проявления in vivo, не проявляет активности по отношению к NTE in vitro.

Морифуса Это с коллегами установили, что ТОКФ претерпевает в организме ряд метаболических изменений, превращаясь в нейротоксичное соединение - 2-(орто-крезил)-4Н-1,3,2-бензодиоксофосфоринан ${ }^{7}$ [17], представленный на рисунке 7.

Его средняя эффективная доза по критерию развития атаксии у кур составляет от 4 до 8 мг/кг. В то же время такая же доза для ТОКФ составляет от 250 до 500 мг/кг. Иными словами, метаболическая активация ТОКФ повышает его нейротоксичность более чем в 60 раз!

Также с ТОКФ и его активным метаболитом связан целый ряд иностранных исследований, направленных на повышение физиологической активности известных органических соединений фосфора за счет явления синергизма. Этот факт даже нашел отражение в широко известном учебном пособии по отравляющим

В англоязычной научной литературе данное соединение также известно под аббревиатурой CBDP. 

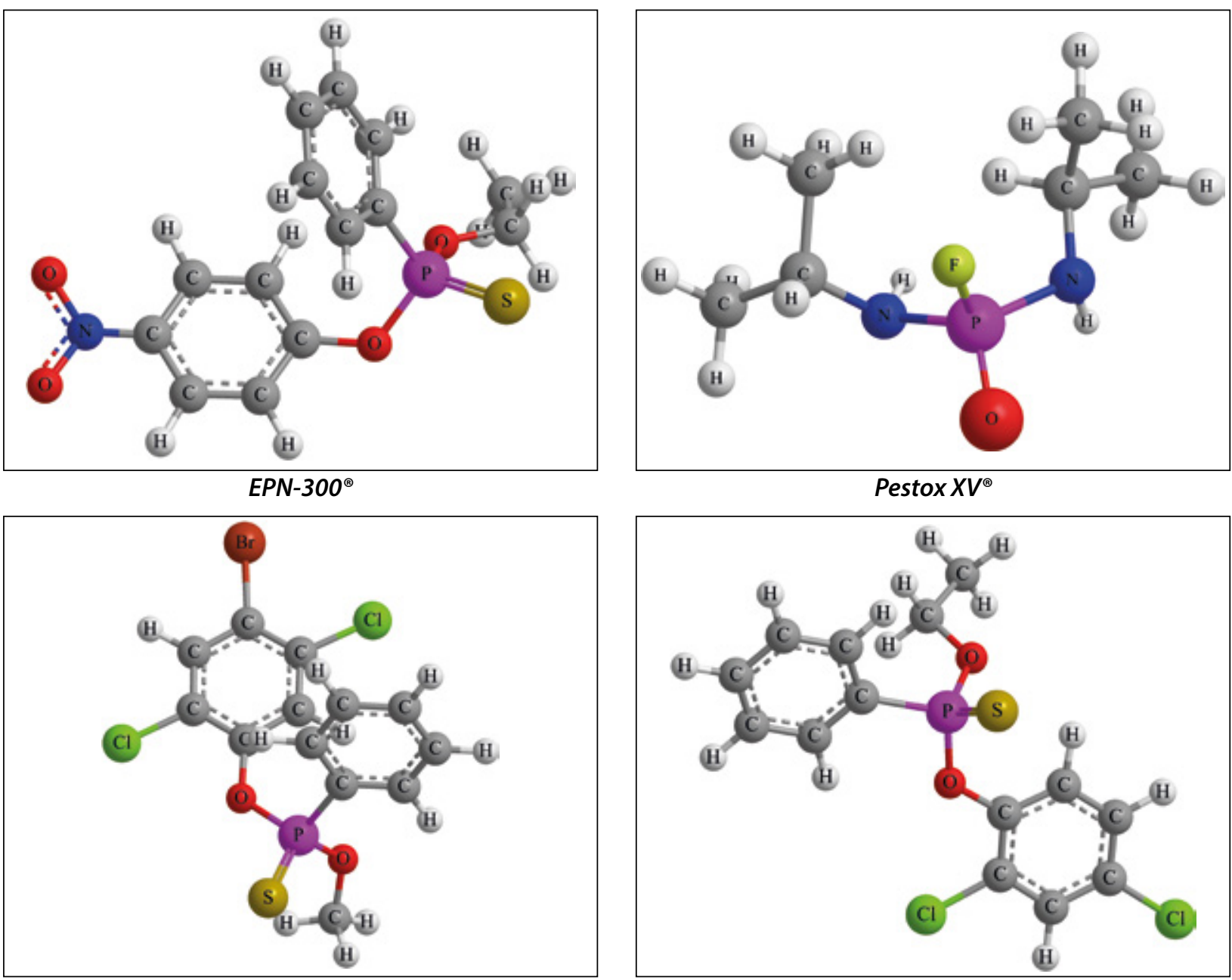

Phosvel $^{\circledR}$

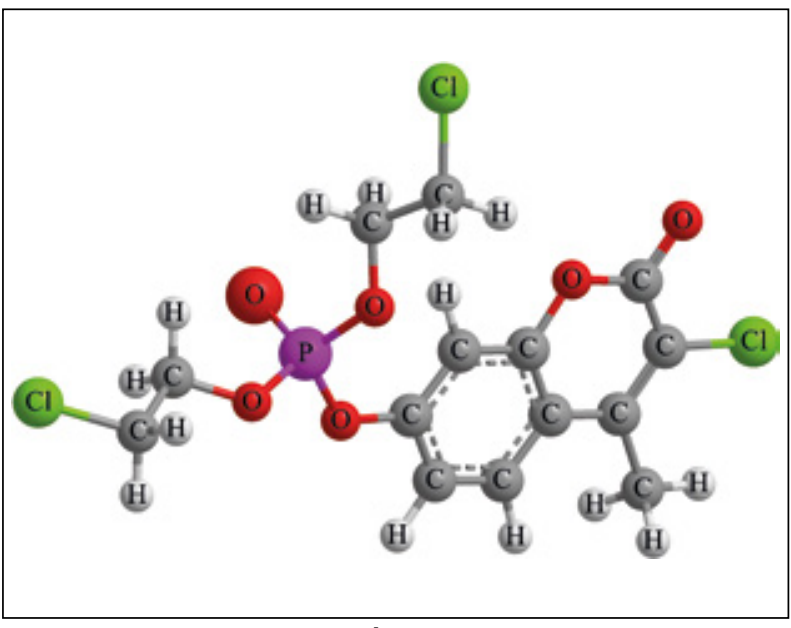

Haloxon $^{\circledast}$

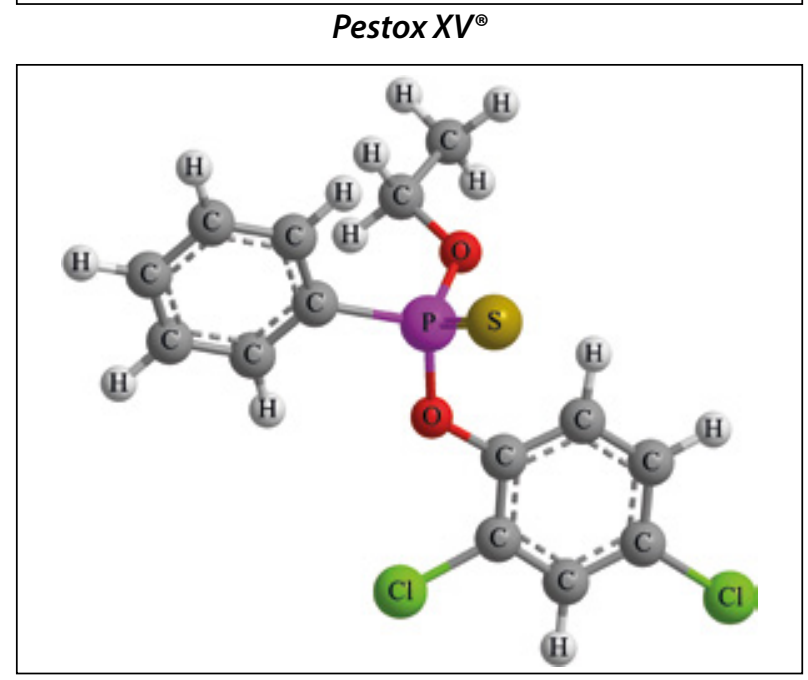

\section{S-Seven ${ }^{\circledast}$}

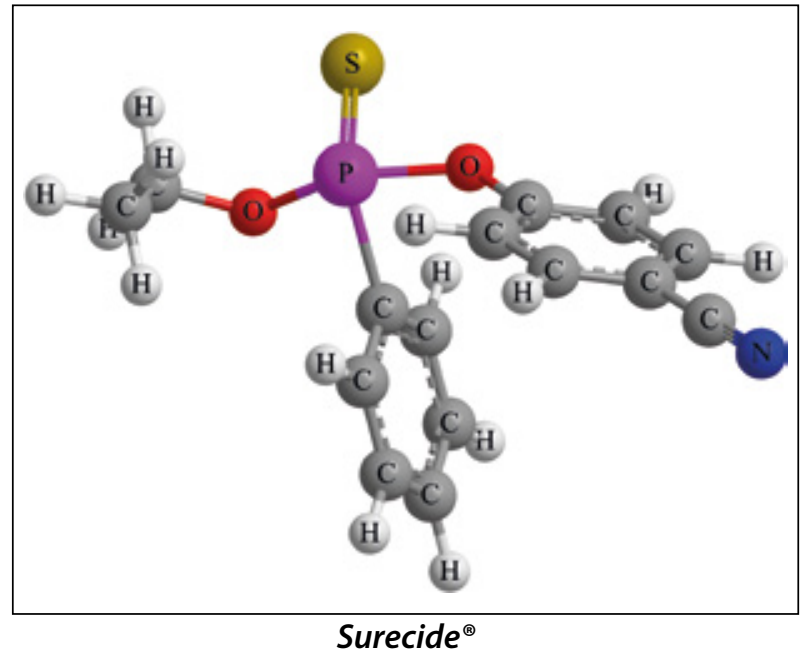

Surecide ${ }^{\circledast}$

Рисунок 6 - Коммерческие пестициды, обладающие отсроченной нейротоксичностью (URL: https://en.wikipedia.org/...; дата обращения: 10.04.2020)

веществам иностранных армий [18]. Там на примере карбофоса показана высокая потенциирующая способность ТОКФ: их совместное введение снижает среднюю смертельную дозу карбофоса с 1100 до 61 мг/кг, а при заблаговре- менном введении ТОКФ - до 8 мг/кг. Анализ периодических научных изданий позволил обнаружить, что такие исследования проводились и с ФОВ, стоявшими на вооружении иностранных государств. 


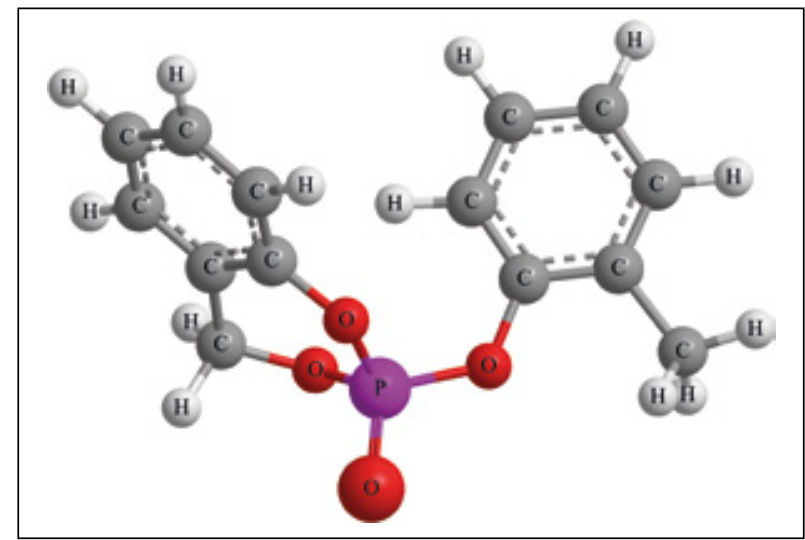

Рисунок 7 - Молекулярная модель 2-(орто-крезил)-4H-1,3,2-бензодиоксофосфоринана (CBDP) нейротоксичного метаболита триортокрезилфосфата [17]

Одной из наиболее интересных ранних публикаций, посвященных синергизму ТОКФ и его метаболитов с другими ФОС, является небольшая статья в журнале Nature за 1961 г., в которой описывается метаболическая активация ТОКФ, вызывающая десятикратное увеличение токсичности малатиона при совместном воздействии [19]. Одним из грантодателей данной работы стало научное подразделение армии США
- U.S. Army Chemical Research and Development Laboratories (грант № DA-CNL-18-108-61-G-6).

Следующая работа, представленная сотрудниками медико-биологической лаборатории Национальной организации оборонных исследований, Рейсвейк, Нидерланды, посвящена изучению совместного воздействия ТОКФ и зарина, меченного атомами $32 \mathrm{P}$, и распределению последнего в тканях организма. В числе прочего было показано, что предварительное введение ТОКФ в дозах 40 мг/кг снижает среднюю смертельную дозу зарина с 210 до 25 мкг/кг, т.е. более чем в 8 раз [20].

В 1971 г. специалистами биомедицинского отдела Управления оборонных исследований, Саффилд, Канада, были проведены исследования по совместному воздействию СВDР и зомана [21]. Было показано, что заблаговременное введение CBDP в дозе 35 мг/кг увеличивает токсичность зомана в 18 раз.

Основываясь на представленных исследованиях, в конце 1970-х гг. специалистами из медицинского отдела Военно-технического института, Белград, Югославия, проведены эксперименты по совместному воздействию СBDР и таких ФОВ, как табун, зарин, VX [22]. Необходимо отметить, что средняя смертельная доза СBDP для белых мышей составляет $107 \pm 5$ мг/кг. Для большей на-

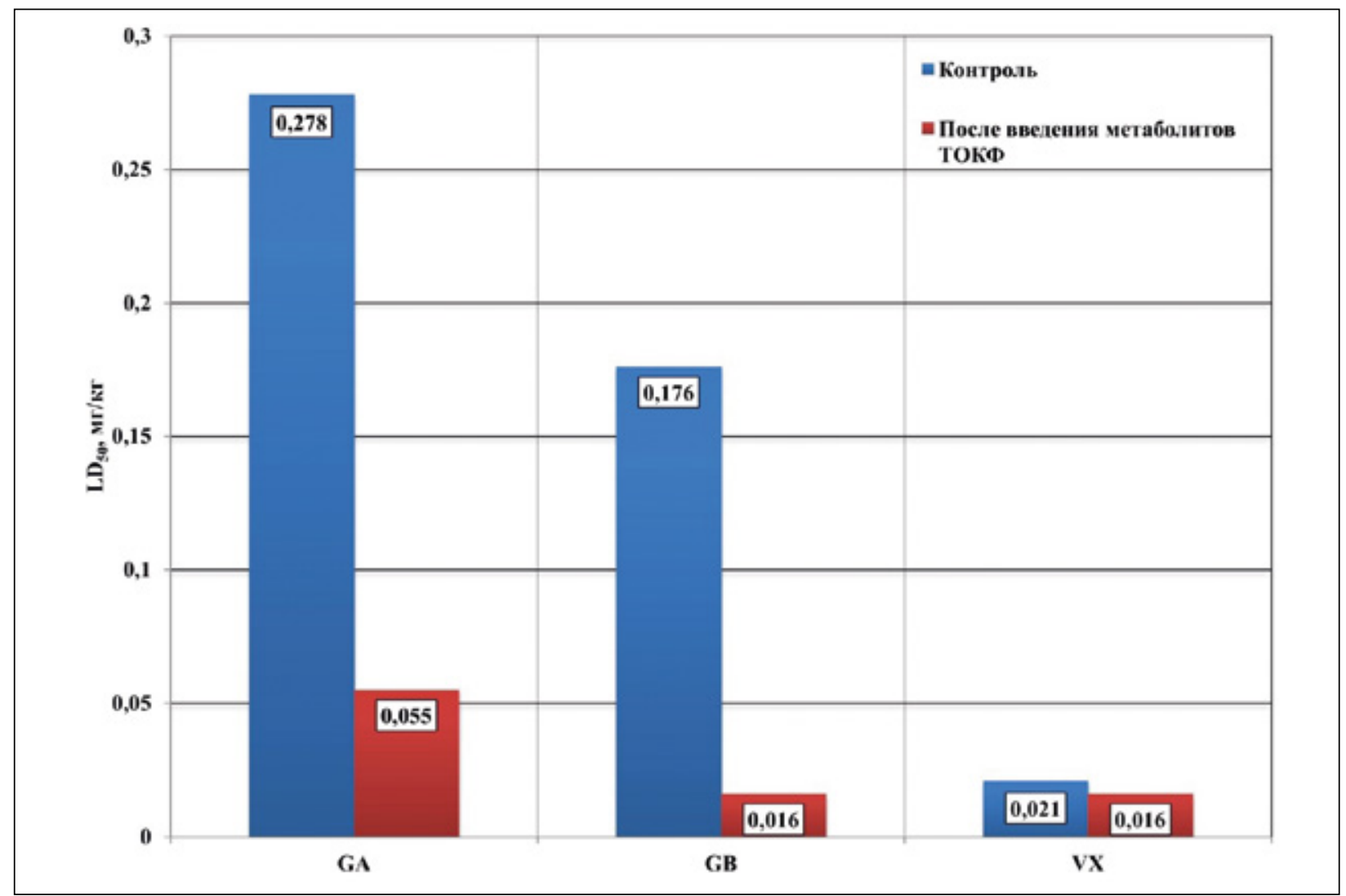

Рисунок 8 - Сравнительные величины средней смертельной дозы ФОВ для контрольной группы животных и после заблаговременного введения СВDР в дозе 50 мг/кг (белые мыши, подкожно) [22] 


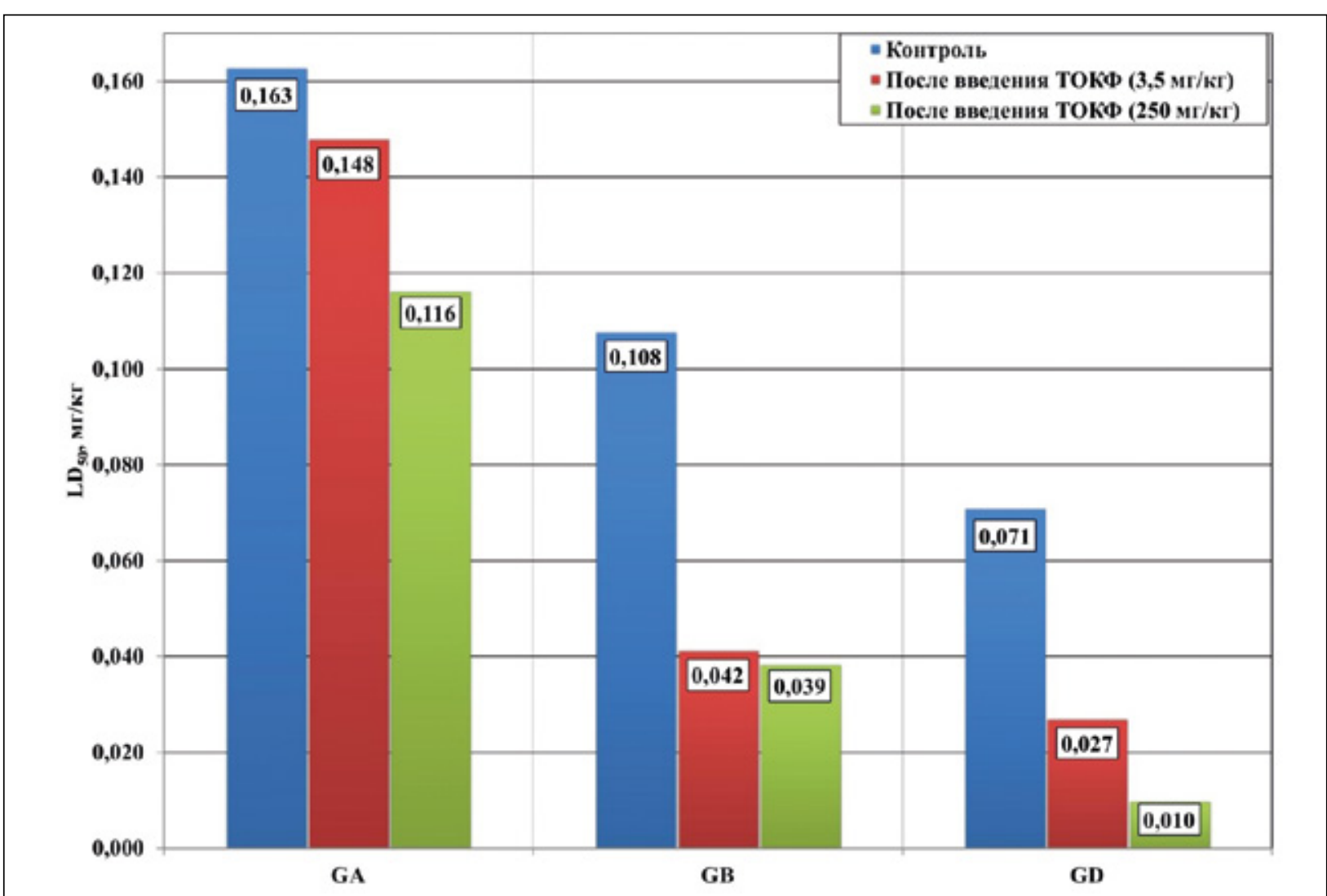

Рисунок 9 - Сравнительные величины средней смертельной дозы ФОВ для контрольной группы животных и после заблаговременного введения ТОКФ в дозах 3,5 и 250 мг/кг (белые крысы, подкожно) [23]

глядности полученные результаты представлены в графическом виде на рисунке 8.

Анализ представленных на рисунке данных показывает, что при совместном воздействии с CBDP токсичность зарина повышается в 11 раз, табуна - в 5 раз. Изменение токсичности VX незначительно и находится на уровне статистической погрешности эксперимента.

Позднее, в 1989 г., специалистами этой же научно-исследовательской организации проведен эксперимент, демонстрирующий увеличение токсичности ФОВ при заблаговременном воздействии ТОКФ в дозах 3,5 и 250 мг/кг [23]. Обобщенные результаты исследований представлены в графическом виде на рисунке 9.

Представленные данные свидетельствуют, что в зависимости от дозы ТОКФ токсичность табуна повышается от 1,1 до 1,4 раз, зарина - от 2,6 до 2,8 раз, зомана - от 2,6 до 7,1 раз.

В 1984 г. специалистами биомедицинского отдела Управления оборонных исследований, Саффилд, Канада, были продолжены начатые ранее [21] исследования по совместному воздействию CBDP и зомана. В представленной статье продемонстрировано изменение средней смертельной дозы зомана в зависимости от количества введенного CBDP [24]. График изменения токсичности зомана представлен на рисунке 10.
Анализ графика показывает увеличение токсичности зомана более чем в 19 раз! В начале 1990-х гг. сотрудниками упомянутой выше медико-биологической лаборатории Национальной организации оборонных исследований, Рейсвейк, Нидерланды, проведено аналогичное исследование с использованием $\mathrm{C}( \pm) \mathrm{P}( \pm)$ стереоизомеров зомана, в котором также показано существенное увеличение токсичности при совместном введении с CBDP [25].

Приведенные примеры являются лишь небольшой частью исследований, направленных на военно-прикладное исследование фосфорорганических соединений, обладающих отсроченной нейротоксичностью. Однако они достаточно ярко демонстрируют заинтересованность иностранных специалистов данным классом соединений.

Отдельные исследователи по совокупности патологических проявлений связывают такое «профессиональное» заболевание, как «Синдром войны в заливе» (Gulf War Syndrome) [26-28], с воздействием на пострадавших ФОС, обладающих отсроченной нейротоксичностью. Однако данная тема является достаточно обширной и требует дальнейших специальных исследований. 


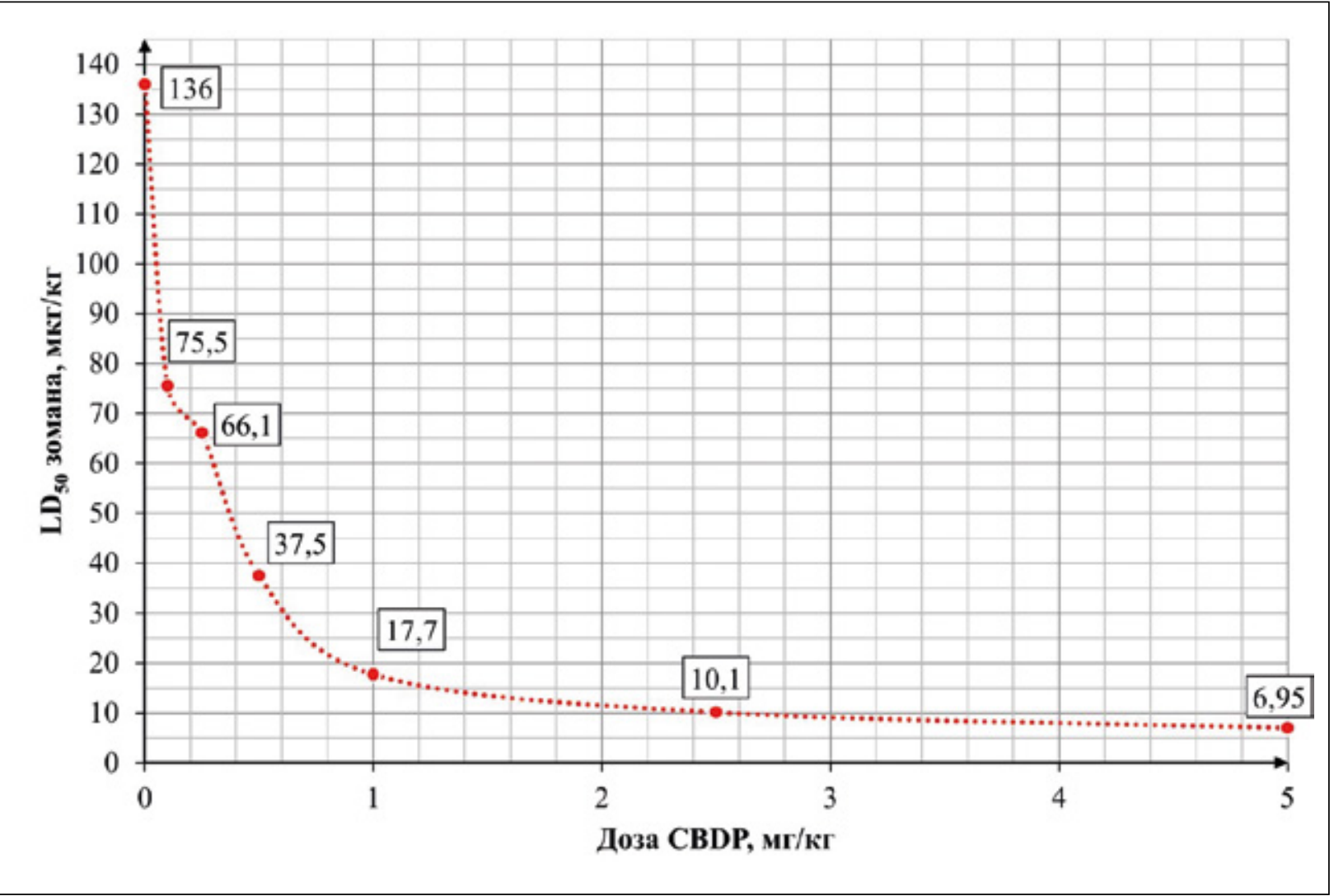

\section{Рисунок 10 - График зависимости средней смертельной дозы зомана (мыши, подкожно) от количества введенного CBDP (мыши, внутривенно) [25]}

По данным Всемирной организации здравоохранения ежегодно более 3 млн человек получают поражения органическими соединениями фосфора различной степени тяжести, причем 10 \% из них заканчиваются летальным исходом [29]. Таким образом, широкое распространение соединений фосфора в различных отраслях промышленности и сельского хозяй- ства, длительный скрытый период и необратимость поражений, вызываемых нейротоксичными ФОС, может обуславливать их потенциальную угрозу для безопасности Российской Федерации, в связи с чем представляется актуальным более пристальный мониторинг состояния зарубежных исследований в рассматриваемой области.

\section{Информация о конфликте интересов}

Авторы заявляют, что исследования проводились при отсутствии любых коммерческих или финансовых отношений, которые могли бы быть истолкованы как потенциальный конфликт интересов.

\section{Сведения о реиензировании}

Статья прошла открытое рецензирование двумя рецензентами, специалистами в данной области. Рецензии находятся в редакции журнала и в РИНЦе.

Список источников

1. Нельга И.А., Медвецкий И.В., Злобин А.В. и др. Химическое оружие: история исследования фосфорорганических отравляющих веществ за рубежом // Вестник войск РХБ защиты. 2019. Т. 3. № 2. C. 175-193.

2. Lorot C. Les Combinaisons de la Creosote dans le Traitement de la Tuberculose Pulmonaire. These de Paris, 1899.
3. Timperley C.M. Best Synthetic Methods: Organophosphorus (V) chemistry. London: Academic Press, 2015.

4. Smith M.I., Elove E., Valaer P.J. Jr., et al. Pharmacological and chemical studies of the cause of socalled Ginger Paralysis // Public Health Reports. 1930. V. 45. № 30. P. 1703-1716.

5. Smith H.V., Spalding J.M.K. Outbreak of 
paralysis in morocco due to ortho-cresyl phosphate poisoning // Lancet. 1959. V. 274. № 7110. P. 1019-1021. https://doi.org/10.1016/S0140-6736(59)91486-2

6. Abou-Donia M. Organophosphorus esterindused chronic neurotoxicity // J. Occup. Health Safety. 2005. V. 21. № 5. P. 408-432.

7. Wexler P. Enciclopedia of toxicology. Bethesda: Academic Press, 2014.

8. Вредные вещества в промышленности. Справочник в трех томах, Т. 3 Неорганические и элементорганические соединения. Л.: Химия, 1977.

9. Johnson M.K. Delayed neurotoxic action of some organophosphorus compounds // Br. Med. Bull. 1969. V. 25. № 3. P. 231-235.

10. Johnson M.K. A phosphorylation site in brain and the delayed neurotoxic effect of some organophosphorus compound // Biochem J. 1969. V. 111. P. 487-495.

11. Johnson M.K. The delayed neurotoxic effect of some organophosphorus compound // Biochem. J. 1969. V. 114. P. 711-717.

12. Chemnitius B.J.M., Haselmeyer K.H., Zech R. Neurotoxic esterase identification of two isoenzymes in hen // Arch. Toxicol. 1983. V. 53. P. 235-244.

13. Прозоровский В.Б., Чепур С.В. Новые данные о несинаптических (дистантных) эффектах фосфорорганических ингибиторов холинэстеразы // Токсикологический вестник. 2001. № 4. С. 2-7.

14. Johnson M.K. Organophosphorus esters causing delayed neurotoxic effect // Arch. Toxicol. 1975. V. 34. P. 259-288.

15. Шрадер Г. Новые фосфорорганические инсектициды. М.: Мир, 1965.

16. Francis B.M., Metcalf R.L., Fisher S.W. Response of laboratory rodents to selected avian delayed neurotoxicants // Arch. Environ. Contam. Toxicol. 1983. V. 12. P. 731-738.

17. Eto M., Casida J.E., Eto T. Hydroxylation and cyclization reactions involved in the metabolism of trio-cresyl phosphate // Biochem. Pharmacol. 1962. V. 11. P. 337-352.

18. Александров В.Н., Емельянов В.И. Отравляющие вещества. М.: «Воениздат», 1990.
19. Casida J.E., Eto M., Baron R.L. Biological activity of tri-o-cresy phosphate metabolite // Nature. 1961. V. 191. P. 1396-1397.

20. Polak R.L., Cohen E.M. The influence of triorthocresylphosphate on the distribution of 32P in the body of the rat after the injection of 32P-sarin // Biochem. Pharm. 1969. V. 18. P. 813-820.

21. McKay D.H., Jardine R.V., Adie P.A. The synergistic action of 2-(o-cresyl)- $4 \mathrm{H}-1,3,2$ benzodioxaphosphorin-2-oxide with soman and physostigmine // Toxicol. Appl. Pharmacol. 1971. V. 20. P. 474-479.

22. Bošković B. The influence of 2-(o-cresyl)4H-1,3,2-benzodioxa-phosphorin-2-oxbde (CBDP) on organophosphate poisoning and its therapy // Arch. Toxicol. 1979. V. 42. P. 207-216.

23. Jokanović M. Role of carboxylesterase in soman, sarin and tabun poisoning in rats // Pharm. Toxicol. 1989. V. 65. P. 181-184.

24. Clement J.G. Importance of aliesterase as a detoxication mechanism for soman (pinacolylmethyl phosphonofluoridate) in mice // Biochem. Pharmacol. 1984. V. 33. № 23. P. 3807-3811.

25. Due A.H. Effect of pretreatment with CBDP on toxicocinetics of soman stereoisomers in rats and guinea pigs // Arch. Toxicol. 1993. V. 67. P. 706-711.

26. Haley R.W., Billecke S., LaDu B.N. Association of low PON1 type Q (type A) arylesterase activity with neurologic symptom complexes in Gulf War veterans // Toxicol. Appl. Pharmacol. 1999. V. 157. P. 227-233.

27. Mackness B., Mackness M.I., Arrol S., et al. Effect of the molecular polymorphisms of human paraoxonase (PON1) on the rate of hydrolysis of paraoxon // Brit. J. Pharmacol. 1997. V. 122. P. 265-268.

28. Crouzier D., LeCrom V.B., Four E., et al. Disruption of mice sleep stages induced by low doses of organophosphorus compound soman // Toxicol. 2004. V.199. P. 59-71.

29. Jalali N., Balali-Mood M., Jalali I., Shakeri M.T. Electrophysiological changes in patients with acute organophosphorous pesticide poisoning // Basic Clin. Pharmacol. Toxicol. 2010. V. 108. P. 251-255.

\section{Об авторах}

Федеральное государственное бюджетное учреждение «33 Центральный научно-исследовательский испытательный институт» Министерства обороны Российской Федерации. 412918, Российская Федерация, г. Вольск-18, ул. Краснознаменная, д. 1.

Иноземиев Валерий Александрович. Начальник института, доктор военных наук.

Нельга Игорь Аликович. Начальник управления, кандидат химических наук.

Медвецкий Игорь Викторович. Начальник отдела, кандидат химических наук.

Комиссаренко Сергей Анатольевич. Ведущий научный сотрудник управления, кандидат химических наук.

Злобин Александр Владимирович. Заместитель начальника отдела, кандидат химических наук.

Третьяков Сергей Вадимович. Старший научный сотрудник, кандидат химических наук.

Шерстюк Артем Валерьевич. Старший научный сотрудник, кандидат химических наук.

Контактная информация для всехавторов: 33cnii-ito@mil.ru Контактное лицо: Шерстюк Артем Валерьевич; 33cnii-ito@mil.ru 


\title{
History of Foreign Studies of Organophosphate Induced Delayed Neuropathy
}

\author{
V.A. Inozemtsev, I.A. Nelga, I.V. Medvetsky, S.A. Komissarenko, \\ A.V. Zlobin, S.V. Tretyakov, A.V. Sherstyuk
}

\begin{abstract}
Federal State Budgetary Establishment «33 Central Scientific Research Test Institute» of the Ministry of Defence of the Russian Federation, Krasnoznamennaya Street 1, Volsk-18, Saratov Region 412918, Russian Federation
\end{abstract}

\begin{abstract}
Certain organophosphates are highly toxic and can be used as chemical warfare agents. However, some classes of organic phosphorus compounds can cause so-called delayed neurotoxicity. Since the discovery of this phenomenon in 1899, extensive research has been conducted on delayed neurotoxicity caused by organophosphates. Mass poisoning of residents of the United States and Morocco in the last century demonstrated the high danger of substances that cause neurotoxicity, and gave a powerful impetus to research into this phenomenon. In addition to delayed effects, some phosphorus compounds potentiate the action of already known chemical warfare agents, increasing their toxicity by more than 10 times. Research in this direction is conducted under the auspices of the defense departments of the United States, Canada and the Netherlands. The wide distribution of phosphorus compounds in various industries and agriculture, the long hidden period and the irreversibility of lesions caused by neurotoxic organic phosphorus compounds, cause their potential threat to the security of the Russian Federation.
\end{abstract}

Keywords: neuropathy target esterase; organic phosphorus compounds; delayed neurotoxicity; synergism; tri-ortho-cresyl phosphate.

For citation: Inozemtsev V.A., Nelga I.A., Medvetsky I.V., Komissarenko S.A., Zlobin A.V., Tretyakov S.V., Sherstyuk A.V. History of Foreign Studies of Organophosphate Induced Delayed Neuropathy // Journal of NBC Protection Corps. 2020. V. 4. № 2. P. 177-188. https://doi.org/10.35825/2587-57282020-4-2-177-188

\section{Conflict of interest statement}

The authors declare that the research was conducted in the absence of any commercial or financial relationship that could be construed as a potential conflict of interest.

Peer review information

The article has been peer reviewed by two experts in the respective field. Peer reviews are available from the Editorial Board and from Russian Science Citation Index database.

\section{References}

1. Nelga I.A., Medvetsky I.V., Zlobin A.V., et al. Chemical Weapons: History of the Study of Organophosphorus Toxic Agents Abroad // Journal of NBC Protection Corps. 2019. V. 3. № 2. P. 175-193 (in Russian).

2. Lorot C. Les Combinaisons de la Creosote dans le Traitement de la Tuberculose Pulmonaire. These de Paris, 1899.

3. Timperley C.M. Best Synthetic Methods: Organophosphorus (V) chemistry. London: Academic
Press, 2015

4. Smith M.I., Elove E., Valaer P.J. Jr., et al. Pharmacological and chemical studies of the cause of socalled Ginger Paralysis // Public Health Reports. 1930. V. 45. № 30. P. 1703-1716.

5. Smith H.V., Spalding J.M.K. Outbreak of paralysis in morocco due to ortho-cresyl phosphate poisoning // Lancet. 1959. V. 274. № 7110. P. 1019-1021. https://doi.org/10.1016/S0140-6736(59)91486-2

6. Abou-Donia M. Organophosphorus ester- 
indused chronic neurotoxicity // J. Occup. Health Safety. 2005. V. 21. № 5. P. 408-432.

7. Wexler P. Enciclopedia of toxicology. Bethesda: Academic Press, 2014.

8. Harmful Substances in Industry. The Reference Book in Three Volumes. V. 3. Inorganic and Elementorganic Compaunds. Leningrad: Chimiya, 1977 (in Russian).

9. Johnson M.K. Delayed neurotoxic action of some organophosphorus compounds // Br. Med. Bull. 1969. V. 25. № 3. P. 231-235.

10. Johnson M.K. A phosphorylation site in brain and the delayed neurotoxic effect of some organophosphorus compound // Biochem J. 1969. V. 111. P. 487-495.

11. Johnson M.K. The delayed neurotoxic effect of some organophosphorus compound // Biochem. J. 1969. V. 114. P. 711-717.

12. Chemnitius B.J.M., Haselmeyer K.H., Zech R. Neurotoxic esterase identification of two isoenzymes in hen // Arch. Toxicol. 1983. V. 53. P. 235-244.

13. Prozorovsky V.B., Chepur S.V. New Data on Non-Synaptic (Distant) Effects of Organophosphorus Inhibitors of Cholincsterase (Literature Review) // Toxicological review. 2001. № 4. P. 2-7 (in Russian).

14. Johnson M.K. Organophosphorus esters causing delayed neurotoxic effect // Arch. Toxicol. 1975. V. 34. P. 259-288.

15. Schrader G. New Organophosphorus Insecticides. Moscow: Mir, 1965.

16. Francis B.M., Metcalf R.L., Fisher S.W. Response of laboratory rodents to selected avian delayed neurotoxicants // Arch. Environ. Contam. Toxicol. 1983. V. 12. P. 731-738.

17. Eto M., Casida J.E., Eto T. Hydroxylation and cyclization reactions involved in the metabolism of trio-cresyl phosphate // Biochem. Pharmacol. 1962. V. 11. P. 337-352.

18. Aleksandrov V.N., Yemelyanov V.I. Toxic Substances, Moscow: Military Publishing, 1990 (in Russian).

19. Casida J.E., Eto M., Baron R.L. Biological activity of tri-o-cresy phosphate metabolite // Nature. 1961. V. 191. P. 1396-1397.

20. Polak R.L., Cohen E.M. The influence of triorthocresylphosphate on the distribution of $32 \mathrm{P}$ in the body of the rat after the injection of 32P-sarin // Biochem. Pharm. 1969. V. 18. P. 813-820.

21. McKay D.H., Jardine R.V., Adie P.A. The synergistic action of 2-(o-cresyl)-4H-1,3,2benzodioxaphosphorin-2-oxide with soman and physostigmine // Toxicol. Appl. Pharmacol. 1971. V. 20. P. 474-479.

22. Bošković B. The influence of 2-(o-cresyl)4H-1,3,2-benzodioxa-phosphorin-2-oxbde (CBDP) on organophosphate poisoning and its therapy // Arch. Toxicol. 1979. V. 42. P. 207-216.

23. Jokanović M. Role of carboxylesterase in soman, sarin and tabun poisoning in rats // Pharm. Toxicol. 1989. V. 65. P. 181-184.

24. Clement J.G. Importance of aliesterase as a detoxication mechanism for soman (pinacolylmethyl phosphonofluoridate) in mice // Biochem. Pharmacol. 1984. V. 33. № 23. P. 3807-3811.

25. Due A.H. Effect of pretreatment with CBDP on toxicocinetics of soman stereoisomers in rats and guinea pigs // Arch. Toxicol. 1993. V. 67. P. 706-711.

26. Haley R.W., Billecke S., LaDu B.N. Association of low PON1 type Q (type A) arylesterase activity with neurologic symptom complexes in Gulf War veterans // Toxicol. Appl. Pharmacol. 1999. V. 157. P. 227-233.

27. Mackness B., Mackness M.I., Arrol S., et al. Effect of the molecular polymorphisms of human paraoxonase (PON1) on the rate of hydrolysis of paraoxon // Brit. J. Pharmacol. 1997. V. 122. P. 265-268.

28. Crouzier D., LeCrom V.B., Four E., et al. Disruption of mice sleep stages induced by low doses of organophosphorus compound soman // Toxicol. 2004. V. 199. P. 59-71.

29. Jalali N., Balali-Mood M., Jalali I., Shakeri M.T. Electrophysiological changes in patients with acute organophosphorous pesticide poisoning // Basic Clin. Pharmacol. Toxicol. 2010. V. 108. P. 251-255.

\section{Authors}

Federal State Budgetary Establishment «33 Central Scientific Research Test Institute» of the Ministry of Defence of the Russian Federation. Krasnoznamennaya Street 1, Volsk-18, Saratov Region 412918, Russian Federation.

Valeriy Alexandrovich Inozemtsev. Head of Institute, Doctor of Military Sciences.

Igor Alikovich Nelga. Head of Department, Candidate of Chemical Sciences.

Igor Viktorovich Medvetsky. Head of Department, Candidate of Chemical Sciences.

Sergey Anatolievich Komissarenko. Leading Researcher, Candidate of Chemical Sciences.

Alexander Vladimirovich Zlobin. Deputy Head of Department, Candidate of Chemical Sciences.

Sergey Vadimovich Tretyakov. Senior Researcher, Candidate of Chemical Sciences.

Artem Valerievich Sherstyuk. Senior Researcher, Candidate of Chemical Sciences. 